\title{
Relation between Health Care Providers' Compliance with Central Venous Catheter Care Bundle Elements and The Length of Stay in Cardiac Care Units, National Heart Institute.
}

\author{
Mohammed A Foda', Ghada M Khalil ${ }^{1}$, Iman M Gaddoue², Mahmoud M Azqul ${ }^{2}$ \\ ${ }^{1}$ Department of public health and community medicine, faculty of medicine, zagazig \\ university, ${ }^{2}$ Department of infection control and epidemiology, National Heart Institute, \\ Egypt.
}

Received: March, 2018 Accepted: May, 2018

\begin{abstract}
Background: Catheter related blood stream infection (CRBSI) is the main complication of central venous catheter (CVC) use which increases the duration of hospital stay and increases the costs of applied health services. Objective: (1) Estimating incidence rate of CRBSI in the National Heart Institute over six months. (2) To identify the relation between the compliance of health care providers to care bundle elements of CVC recommended by CDC and hospital LOS. Methods: A Prospective cohort study was conducted on one hundred and eleven cardiac patients in cardiac care units, (NHI) from August 2017 to January 2018. All patients subjected to central venous catheter (CVC) in cardiac care units, NHI, were included except: Patients with obvious source of infection, patients having infective endocarditis and patients whose catheter was put outside the NHI. Results: Noncompliance of health care providers to care bundle elements of CVC of Centers for Disease Control and Prevention (CDC) and CRBSI occurrence are statistically significant factors which increase hospital length of stay (LOS). Conclusion: This study revealed that noncompliance to care bundle elements through insertion and handling of CVC leads to increase length of hospital stay. Recommendation: Health care providers should adhere to care bundle elements recommended by CDC during insertion and handling of CVC.
\end{abstract}

Keywords: Central venous catheter, Length of stay, Blood stream infection.

Corresponding author: Mahmoud M Azqul Email: mahmoudms@zu.edu.eg

\section{Introduction}

Central venous Catheters (CVCs) play an important role in facilitating infusion, drug administration, repeated sampling and close monitoring in seriously ill patients. ${ }^{1}$ The prevalence of $\mathrm{CVCs}$ utilization in intensive care patients was reported as forty eight percent. ${ }^{2}$ Use of CVCs had been associated with many complications but most common increased risk of catheter-related bloodstream infections (CRBSIs). ${ }^{3}$ Incidence rate was reported as a function of total CVC count or CVC-days as $4.3 \%$ to $26 \%$ and 0.46 to 30 per 1000 catheter-days, respectively. ${ }^{4}$ CRBSI remain a problem for hospitals causing increase length of stay (LOS) of an average of 10.4 days and increase in costs more than $\$ 45,000$ per occurrence. ${ }^{5}$ Patient's LOS usually is a good indicator for quality and efficiency of applied health care. ${ }^{6}$ Increase length of stay is a result of poor health conditions. ${ }^{7}$ Long length of stay described if patient's hospital stay is more than 30 days. $^{8}$ Several risk factors of CRBSI had been identified and were broadly classified into patient related factors, catheter related factors, or 
medical staff related factors. ${ }^{9}$ The medical staff can manage their related factors by the strict use of antiseptic techniques and close adherence to the guidelines recommended by the Centers for Disease Control and prevention (CDC) guidelines which in role decrease LOS. $^{10}$

Objectives: (1) Estimating incidence rate of CRBSI in the National Heart Institute over six months. (2) To identify the relation between the compliance of health care providers to care bundle elements of CVC recommended by CDC and hospital LOS.

\section{Methods}

Study design and setting: A Prospective cohort study was conducted on one hundred and eleven cardiac patients in cardiac care units, (NHI) from August 2017 to January 2018. All patients subjected to central venous catheter (CVC) in cardiac care units, NHI, were included except: 1 . Patients with obvious source of infection (fever, pneumonia, urinary tract infection, cellulitis, and septicemia) identified by history, clinical examination, blood culture, chest X-ray, urine examination, and relevant investigations. 2. Patients having infective endocarditis. 3. Referred patients whose catheter was put outside the NHI.

Sample size: As the number of cases with central venous catheters admitted to cardiac care units, (NHI), who matched inclusion criteria, were about 17 cases per month. So, the period of six months' sample calculated to be 102 patients was taken as a comprehensive sample.

Activities: 1-Active surveillance for calculating the incidence of central venous CRBSI: Incidence of CVC related $\mathrm{BSI}=$ number of $\mathrm{CVC}$ related BSIs/number of CVC-days $* 1000^{(11)}$.

Surveillance Methodology: The collection of data for BSIs and their corresponding denominator data was performed using active, patient-based, prospective surveillance of the population at risk (i.e., patients who have central line). This means that the infection was sought out during a patient's stay by screening a variety of data sources, such as microbiology reports, patient records, clinical notes, temperature charts which were recorded in our questionnaire and finally the length of stay at time of discharge (considered prolonged if more than 30 days). ${ }^{12}$

CVC related BSIs ${ }^{13}$ : Patients with $\mathrm{CVC}$ for more than $48 \mathrm{~h}$ with clinical signs or symptoms of infection which may be local signs such as erythema, pus drainage, swelling, pain and tenderness at site of insertion and/or systemic signs such as temperature $\geq 38 \mathrm{C}$, chills, oliguria, hypothermia and hypotension with no other obvious source of infection confirmed laboratory when a culture of the catheter tip demonstrated substantial colonies of an organism is the same to those found in the bloodstream.

Denominator: Central venous catheter - days (CVC-days): At the same time every day, the number of patients with CVCs was counted, if a patient with central lines is temporarily out the unit, the central line day is counted. If patient with CVC has been discharged or transferred to another unit, the central line day is not counted. At the end of the study period, the sum of CVCs days count was recorded. ${ }^{11}$

Extra period of ICU stays: It was calculated by subtracting the average length of hospital stay of patients without CRBSI from that in patients with CRBSI in the same study period ${ }^{(14)}$.

2-Observation of risk factors ${ }^{15}$ : All patients with CVC matched with inclusion criteria were included on the observational data of risk factors. The observation included the conditions of care bundle elements of the catheter recommended by CDC (hand hygiene by 
inserter, maximal barrier precautions, use of chlorohexidine gluconate and handling

Table 1: Socio-demographic characteristics of studied sample of patients in cardiac care units

\begin{tabular}{|c|c|c|c|c|c|}
\hline & \multicolumn{2}{|c|}{$\begin{array}{c}\begin{array}{c}\text { Length of stay <30 days } \\
(n=102)\end{array} \\
\end{array}$} & \multicolumn{2}{|c|}{$\begin{array}{c}\text { Length of stay } \geq 30 \text { days } \\
(n=9)\end{array}$} & $\begin{array}{c}P \\
\text { value }\end{array}$ \\
\hline Gender & $\mathrm{N}$ & $\%$ & $\mathrm{~N}$ & $\%$ & \\
\hline Male $(\mathrm{n}=61)$ & 56 & 91.8 & 5 & 8.2 & .970 \\
\hline Female $(\mathrm{n}=50)$ & 46 & 92 & 4 & 8 & \\
\hline & Median (IQR) & & Median (IQR) & & \\
\hline Age (years) & $38(12-53)$ & & $55(26-65)$ & & $.191 *$ \\
\hline & Mean \pm SD & & Mean \pm SD & & \\
\hline $\begin{array}{l}\text { Length of stay in } \\
\text { days }\end{array}$ & $13.29 \pm 2.95$ & & $32.67 \pm 2.73$ & & $.000 * *$ \\
\hline $\begin{array}{l}\text { History of CRBSI: } \\
\text { No }(n=100) \\
\text { Yes }(n=11)\end{array}$ & $\begin{array}{l}\mathrm{N} \\
98 \\
4\end{array}$ & $\begin{array}{r}\% \\
98 \\
36.36\end{array}$ & $\begin{array}{l}\mathrm{N} \\
2 \\
7\end{array}$ & $\begin{array}{c}\% \\
2 \\
63.64\end{array}$ & .000 \\
\hline
\end{tabular}

*Data are expressed by median and IQR. P value by Mann Whitney U test.

** Data are expressed as mean and SD. P value by Independent-Samples t-Test.

Otherwise by Chi-Square test.

Table 2: length of stay in days, mean \pm SD in patients with and without CRBSI and extra length of stay

\begin{tabular}{|l|l|l|l|}
\hline $\begin{array}{l}\text { Length of stay in } \\
\text { days }(\mathrm{n}=1650)\end{array}$ & \multicolumn{1}{|c|}{ CRBSI $(\mathbf{n = 1 1})$} & NO CRBSI $(\mathbf{n = 1 0 0})$ & \multicolumn{1}{c|}{ P value } \\
& $(\mathrm{n}=305)$ & $(\mathrm{n}=1345)$ & $.000^{*}$ \\
Mean \pm SD & $27.73 \pm 6.35$ & $13.45 \pm 4.04$ & \\
\hline \multicolumn{2}{|c|}{ Extra length of stay $=14.28$ days } \\
\hline
\end{tabular}

*Data are expressed as mean and SD. P value by Independent-Samples t-Test.

care after insertion). The observation of duration of use of CVC (a catheter period was defined as the period from implantation of the CVC or access to implanted ports until development of CRBSI and/or CVC removal). ${ }^{16}$

\section{Administrative consideration and} Ethical consideration:

An official permission to conduct the study at the cardiac care unit was obtained from the National Heart Institute and the institutional review board of faculty of medicine, Zagazig University. The title and objectives of this study were explained to them to insure their cooperation. The local authority and manager of NHI was informed about the nature and steps of the study and written consent was taken, the study group was informed about the nature and the purpose of the study and verbal informed consent was taken before interview. The study group was not exposed to any harm or risk and Patient's data was confidential.

Statistical analysis: Data were entered and analyzed using SPSS software (version 21).

Quantitative data were initially tested for normality using Kolmogorov-Smirnov and Shapiro-Wilk's test with data being normally distributed if $\mathrm{p}>0.050$. Quantitative data were expressed as mean \pm standard deviation (SD) if normally distributed or median and interquartile range (IQR) if not. 
Table 3: The level of adherence of health care providers with guidelines of CVC insertion by CDC and length of stay (average and long).

\begin{tabular}{|c|c|c|c|c|c|c|c|}
\hline \multirow[t]{2}{*}{ Variables } & \multirow{2}{*}{$\begin{array}{c}\begin{array}{c}\text { Length of stay } \\
(<30 \text { days })\end{array} \\
\text { N = 102 } \\
\text { Yes }(n, \%) \\
\text { No }(n, \%)\end{array}$} & \multirow{2}{*}{$\begin{array}{l}\text { Length of stay } \\
\begin{array}{r}(\geq 30 \text { days) } \\
N=9 \\
\text { Yes }(n, \%) \\
\text { No }(n, \%)\end{array}\end{array}$} & \multirow[t]{2}{*}{$\begin{array}{l}\text { Chi- } \\
\text { square }\end{array}$} & \multirow[t]{2}{*}{$P$ value } & \multirow[t]{2}{*}{$\begin{array}{l}\text { Odds } \\
\text { ratio }\end{array}$} & \multicolumn{2}{|c|}{$\begin{array}{c}\text { Confidence } \\
\text { level } \\
95 \%\end{array}$} \\
\hline & & & & & & Lower & Upper \\
\hline $\begin{array}{l}\text { Perform Hand } \\
\text { Hygiene } \\
\text { Before } \\
\text { Insertion }\end{array}$ & $\begin{array}{l}86,84.31 \\
16,15.69\end{array}$ & $\begin{array}{l}3,33.34 \\
6,66.66\end{array}$ & 13.52 & $<0.001 *$ & 10.75 & 2.43 & 47.46 \\
\hline Over head & $\begin{array}{l}91,89.22 \\
11,10.78\end{array}$ & $\begin{array}{l}2,22.23 \\
7,77.77\end{array}$ & 27.32 & $<0.001 *$ & 28.95 & 5.33 & 157.14 \\
\hline Mask & $\begin{array}{l}\text { 70, } 68.63 \\
32,31.37\end{array}$ & $\begin{array}{l}3,33.34 \\
6,66.66\end{array}$ & 4.57 & $.032 *$ & 4.37 & 1.029 & 18.60 \\
\hline Gown & $\begin{array}{l}88,86.27 \\
14,13.73\end{array}$ & $\begin{array}{l}2,22.23 \\
7,77.77\end{array}$ & 22.119 & $<0.001 *$ & 22 & 4.14 & 116.82 \\
\hline $\begin{array}{l}\text { Perform skin } \\
\text { anti-sepsis } \\
\text { with } 7.5 \% \\
\text { Chlorhexidine } \\
\text { with alcohol }\end{array}$ & $\begin{array}{r}96,94.12 \\
6,5.88\end{array}$ & $\begin{array}{l}2,22.23 \\
7,77.77\end{array}$ & 41.34 & $<0.001 *$ & 56 & 9.49 & 330.33 \\
\hline $\begin{array}{l}\text { Cover the site } \\
\text { with sterile } \\
\text { gauze }\end{array}$ & $\begin{array}{r}92,90.20 \\
10,9.80\end{array}$ & $\begin{array}{l}6,66.68 \\
3,33.32\end{array}$ & 4.42 & $.035 *$ & 4.60 & .99 & 21.28 \\
\hline $\begin{array}{l}\text { Perform Hand } \\
\text { Hygiene } \\
\text { Before } \\
\text { handling with } \\
\text { catheter }\end{array}$ & $\begin{array}{l}\text { 70, } 68.63 \\
32,31.37\end{array}$ & $\begin{array}{l}\text { 1, 11.12 } \\
8,88.88\end{array}$ & 11.869 & $.001 *$ & 17.50 & 2.099 & 145.86 \\
\hline $\begin{array}{l}\text { Scrub the } \\
\text { access port } \\
\text { prior to each } \\
\text { use with an } \\
\text { appropriate } \\
\text { antiseptic }\end{array}$ & $\begin{array}{l}83,81.37 \\
19,18.63\end{array}$ & $\begin{array}{l}2,22.23 \\
7,77.77\end{array}$ & 16.132 & $<0.001^{*}$ & 15.28 & 2.940 & 79.50 \\
\hline $\begin{array}{l}\text { Access } \\
\text { catheters only } \\
\text { with sterile } \\
\text { devices }\end{array}$ & $\begin{array}{r}99,97.06 \\
3,2.94\end{array}$ & $\begin{array}{l}3,33.34 \\
6,66.66\end{array}$ & 45.076 & $<0.001 *$ & 66 & 10.910 & 399.27 \\
\hline
\end{tabular}

Data are expressed as count (percent). P value by Chi-Square test.

Independent-Samples t-test was used if data were normally distributed in both groups. The non-parametric alternative Mann-Whitney U test was used if not.

Qualitative data were expressed as count and percent and Chi-Square test was used for it. For any of the used tests, results were considered as statistically significant if $\mathrm{p}$ value $\leq 0.05$.

\section{Results}

This study included 111 cardiac patients with CVC; $55 \%$ of patients were males, $45 \%$ were females, the study shows that 


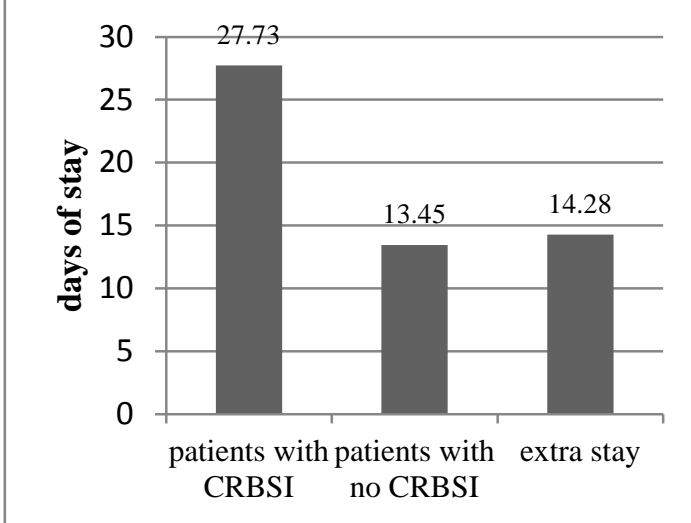

Figure 1: Mean hospital length of stay in patients with and with no CRBSI and the estimated extra stay

the Median and IQR of age regarding hospital LOS $<30$ days is 38(12-53), while in hospital $\operatorname{LOS} \geq 30$ days is $55(26$ 65) with no statistically significant difference of age to the hospital LOS. Extra LOS is 14.28 days as the mean \pm $\mathrm{SD}$ in CRBSI is $27.73 \pm 6.35$ and in No CRBSI is $13.45 \pm 4.04$ with statistically significant difference showed in (table 1,2 and figure 1). The incidence rate of CRBSI is $7.95 / 1000$ catheter days. and table (1) shows also the comparisons between patients' length of stay (average and long) regarding occurrence of CRBSI showing that 7 patients $(6.3 \%)$ of all included patients have long LOS (more than 30 days) are associated with CRBSI and LOS is a significant factor for occurrence of CRBSI.

Table (3) compares between patients' length of stay (>30 and $<30$ days) regarding care bundle elements of CVC recommended by $\mathrm{CDC}$ and shows that these elements are significant risk factors for long LOS. physicians' hand hygiene performance before CVC insertion (OR: 10.75, 95\%CI: 2.43-47.46), physicians with overhead before CVC insertion (OR: 28.95, 95\%CI: 5.33-157.14), physicians with mask before CVC insertion (OR: 4.37, 95\%CI: 1.02-18.60), physicians wearing gown before CVC insertion (OR: 22.00, 95\%CI:4.14116.82), performing skin anti sepsis (OR: 56.00, 95\%CI: 9.49-330.33), covering skin with sterile gauze (OR: 4.60,
95\%CI: .99-21.28), performing hand hygiene before handling with $\mathrm{CVC}$ (OR:17.50, 95\%CI:2.09-145.86), scrubbing the port prior to each use with an appropriate antiseptic (OR:15.28, 95\%CI: 2.94-79.50) and access catheters only with sterile devices (OR: 66.00, 95\%CI: 10.91-399.27).

\section{Discussion}

CVCs usage is common in intensive care units with critically ill patients, as its use not only help in clinical improvement but also in patients' quality of life. Unfortunately, CRBSI is a complication of CVC insertion which in role leads to increase patients' hospital LOS. ${ }^{15}$

In the current study, the investigators studied the compliance of health care providers to $\mathrm{CVC}$ care bundle elements recommended by centers for disease control and prevention (CDC) and its impact on patients' hospital LOS.

Total number of participated patients was 111 patients, 61 patients were males $(55 \%)$ and 50 were female's patients $(45 \%)$ with no statistically significant difference regarding the gender in increasing LOS. Wang et al. ${ }^{17}$ reported that gender was not a significant risk factor which agree with the study.

The study showed that the Median and IQR of age regarding hospital LOS $<30$ days was 38(12-53), while in hospital LOS $\geq 30$ days was 55(26-65) with no statistically significant difference of age to the hospital LOS. Wang et al. (17) showed the same result as the study.

The study showed that the incidence rate of CRBSI 7.95/1000 catheter days in NHI. Hajjej et al. ${ }^{(18)}$ reported that the incidence of CRBSI in France was $0.9 / 1000$ catheter days according to data of "the warning Network, investigation and surveillance of nosocomial infection" which is lower than the study incidence while in developing countries it was $12 / 1000$ catheter days which is higher than the study incidence. Holroyd et al. ${ }^{(5)}$ reported incidence rate was reported as 
a function of total CVC count or CVCdays as $4.3 \%$ to $26 \%$ and 0.46 to 30 per 1000 catheter-days, respectively.

The current study showed significant difference between LOS in patients with and without CRBSI in the studied sample of patients and the extra LOS is 14.28 days. This is consistent with the findings of Robles et al. ${ }^{18}$ and Abdelsalam et al. ${ }^{19}$ who reported that increase incidence of CRBSI lead to increase patient's hospital LOS. The study also showed that care bundle elements (hand hygiene before insertion, sterile gloves, overhead, mask, gown, performing skin anti sepsis, performing hand hygiene before handling, scrubbing the port prior to each use with an appropriate antiseptic and access catheters only with sterile devices) are significant risk factors for increase the LOS. Pamela et al. ${ }^{(15)}$ observed the same risk factors with statistical significance and reported increase hospital (LOS) with CRBSI occurrence.

\section{Conclusion and Recommendations:}

The current study reported that CRBSI incidence is 7.95/1000 catheter days and increase in LOS in patients with a noncompliance with care bundle elements recommended by CDC. So, it is recommended for Health care providers to closely adhere to care bundle elements recommended by CDC during insertion and handling of CVC which in role will decrease the LOS and incidence of CRBSI.

\section{References}

1. Ren H, Colletta A, Koley D, Wuc J, Xi C, Major T C, et al (2015): Thromboresistant/anti-biofilm catheters via electrochemically modulated nitric oxide release. Bio electro chemistry; 104:10-16.

2. Salama M F, Jamal W, Al Mousa H and Rotimi V (2016): Implementation of central venous catheter bundle in an intensive care unit in Kuwait: Effect on central line-associated bloodstream infections. Journal of Infection and Public Health; 9: 34-41.

3. Lona-Reyes J C, López-Barragán B, De La Rosa A J, Pérez-Molina J J, and Ascencio-Esparza E P (2016): Central venous-catheter related bacteremia: incidence and risk factors in a hospital in western Mexico. Boletín Médico del Hospital Infantil de México (English Edition); 73 (2):105-110.

4. Napalkov P, Felici DM, Chu LK, Jacobs JR and Begelman SM (2013): Incidence of catheter-related complications in patients with central venous or hemodialysis catheters: a health care claims database analysis. Bio Medical Center Cardiovascular Disorder; 13(1):86.

5. Holroyd J L, Vasilopoulos T, Rice M J, Rand K H and Fahy B G (2017): Incidence of central venous catheter hub contamination. Journal of Critical Care; 39: 162-168.

6. Borghans I, Heijink R, Kool T, Lagoe RJ, Westert GP (2008): Benchmarking and reducing length of stay in Dutch hospitals. Bio Medical Service Health Service Research; 24:8220.

7. Bo M, Fonte G, Pivaro F, Bonetto M, Comi C, Giorgis V, et al (2015): Prevalence of and factors associated with prolonged length of stay in older hospitalized medical patients. Geriatric and Gerontology International; (9).

8. Barba R, Marco J, Canora J, Plaza S, Juncos S, Hinojosa J, et al (2015): Prolonged length of stay in hospitalized internal medicine patients. European Journal of internal medicine; 26:772-775. 9. Shah H, Bosch W, Thompson KM and Hellinger WC (2013): Intravascular catheter-related bloodstream infection. The Neuro hospitalist; 3(3):144-51.

10. Hammarskjöld F, Berg S, Hanberger H, Taxbro K and Malmvall B (2014): Sustained low incidence of central venous catheter-related infections over six years in a Swedish hospital with an 
active central venous catheter team. American Journal of Infection Control; 42:122-8.

11. Association for Professionals in Infection Control and Epidemiology (2009): Guide to the Elimination of Catheter-Related Blood Stream Infections.

12. Mozaffari $\mathrm{K}$, Bakhshandeh $\mathrm{H}$, Khalaj H and Soudi H (2013): Incidence of catheter-related infections in hospitalized cardiovascular patients. Research in Cardiovascular Medicine; 2 (2):99-103.

13. Clinical and Laboratory Standards Institute (2007): Performance standards for antimicrobial susceptibility testing: Seventeenth informational supplement Antimicrobial Susceptibility Testing (AST) Recommendations M100-S17.

14. El Nakera A, Meawed $\mathrm{T}$ and Aboserea M (2012): Base LineSurveillance of Device Associated Infections (DAIS) in A Surgical-Medical Intensive Care Unit at Zagazig University Hospital, Egyptian Journal Microbiology; 32(60).

15. Pamela $\mathrm{P}$, Antonio A, Elena $\mathrm{S} \mathrm{R}$, María G A, José P, Luis Fernando P G, et al (2015): Risk factors and biofilm detection on central venous catheters of patients attended at tertiary hospital. Micron; 78:33-39.

16. Wagner J, Schilcher G, ZollnerSchwetz I, Hoenigl M, Valentin T, Ribitsch W, et al (2013): Microbiological screening for earlier detection of central venous catheter-related bloodstream infections. Stiching European Society for Clinical Investigation Journal Foundation; 43:964-969.

17. Wang $\mathrm{T} \mathrm{Y}$, Lee $\mathrm{K} \mathrm{D}$, Chen $\mathrm{P} \mathrm{T}$, Chen M C, Chen Y Y, Huang C E, et al. Incidence and risk factors for central venous access port-related infection in Chinese cancer patients. Journal of the Formosan Medical Association 2015; 114:1055-1060.

18. Hajjej z, Nasri M, Sellami W, Gharsallah H, Labben I and Ferjani M (2014): Incidence, risk factors and microbiology of central vascular catheter - related blood stream infection in an intensive care unit. Journal of infection and chemotherapy; 20:163-168.

19. Robles M A, Ojha RP, Gonzalez M, Diezbarroso K O, Acosta E D, Jackson BE, et al (2014). Blood Stream Infections and inpatient Length of stay among pediatric cancer patients with febrile neutropenia in Mexico City; 42:12351237.

20. Abdelsalam N, El Nemr W, Fahmy $\mathrm{H}$ and Abed El Razek GH (2013): An interventional Study to Decrease Central Venous Catheter Related Blood Stream Infection in Intensive Care Units, Zagazig University Hospital, MD thesis in Public Health and Community Medicine, Faculty of Medicine, Zagazig University. 